\title{
A study of the chemical effect of marble and granite slurry on green mortar compressive strength
}

\author{
Shereen K. Amin ${ }^{1}$, Mostafa E. Allam², Gihan L. Garas ${ }^{2 *}$ and Hisham Ezz ${ }^{2}$
}

\begin{abstract}
Background: The marble and granite industries in Egypt produce a vast amount of by-product slurry waste that could be used in green mortar production suitable for construction purposes. This research highlights the effect of the chemical constituents of marble and granite waste powders on the compressive strength of the green concrete produced. A chemical analysis of the constituents of granite and marble wastes was compared with those of the cement to study the effect of these components on the hydration reaction inside the mixture. The experiment was based on replacing the same proportions of sand and cement in the green concrete mixes with each of granite and marble waste powders after dissolving it in the water content.

Results: The study revealed that by replacing $5 \%$ of cement in (NC5) mix, $10 \%$ of sand in (NF10) mix, as well as $5 \%$ of cement and $10 \%$ of sand in (NC5 + NF10) mix, by granite waste powder, the compressive strength values increased by $33 \%, 39 \%$, and $41 \%$, respectively. This was due to the presence of more than $26 \%$ fine free silica particles in granite which undergo pozzolanic reaction with calcium hydroxide present in mortar pores producing calcium silicate hydrate (CSH) crystals resulting in high strength to the cement mortar. For the same mixes containing marble powder, the compressive strength showed less values by $-14 \%, 10 \%$, and 0\% for NC5, NF10, and NC5 + NF10 mixes, respectively, when compared to the control mix values.
\end{abstract}

Conclusion: Although the waste particles worked as filler, it was observed that its presence in the mixture improved the particle packing and increased the cohesion of the composites.

Keywords: Marble slurry, Granite powder, Pozzolanic reaction, Hydration

\section{Introduction}

Ornamental stones, specifically marble and granite, are common building materials being widely used in construction processes. Handling as well as disposal of these stones' wastes is considered one of the major environmental and land pollution problems due to both its highly alkaline nature, and its manufacturing and processing techniques, which impose a health threat to the surroundings (Hamza et al. 2011).

Several researches worldwide attempted to use these industrial by-products efficiently in producing mortar and concrete on an experimental scale. Marble and granite wastes (MGWs) do not require any processing

\footnotetext{
* Correspondence: gihangaras@yahoo.com

${ }^{2}$ Civil Engineering Department, Engineering Research Division, National

Research Centre, Dokki, Egypt

Full list of author information is available at the end of the article
}

before its use in mortar and concrete production. Moreover, its physical and chemical properties are suitable for making concrete products. Also, due to its finesse, MGW is a promising material which acts as a microfiller in cement aggregate matrix (Ramos et al. 2013; Bacarji et al. 2013).

Bahar (2010) studied the effect of using marble dust waste as a fine material on the mechanical properties of the concrete mix. The study revealed that substituting the very fine aggregate passing through a $0.25-\mathrm{mm}$ sieve by marble waste performed better than the control mix in terms of compressive strength. Marble dust had a filler effect at an early age and played a noticeable role in the hydration process. The SEM investigations indicated a difference between the appearance of $\mathrm{CH}$ crystals with and without marble dust addition, verifying the fact 
that the marble dust played a noticeable role during the hydration process.

Manpreet et al. (2017a, 2017b) indicated in his study that replacing $15 \%$ of the cement content in the concrete mix at a water to cement ratio of 0.35 with marble slurry would decrease the water permeability and abrasion of the mix. Higher replacement ratios increased the density of the mix and reduced water penetration in the long term.

Similarly, Sarbjeet et al. (2015) observed that the optimum replacement percentage of marble waste for both cement and sand was found 15\% to produce paver concrete blocks. Increasing this replacement percentage affected negatively the compressive strength of the produced blocks. The percentage increment in the compressive strength for the optimum mix is greater in case of sand replacement as compared to the cement replacement.

Additional studies were conducted to evaluate the effect of using granite waste as a replacement for cement and sand in the concrete and mortar mixes. Shehdeh (2016) observed that substitution of $10 \%$ of sand by weight with granite powder in concrete resulted in a maximum increase in compressive strength to approximately $500 \mathrm{~kg} / \mathrm{cm}^{2}$ compared to $365 \mathrm{~kg} / \mathrm{cm}^{2}$ of control concrete and an increase in splitting tensile strength to $30 \mathrm{~kg} / \mathrm{cm}^{2}$ compared to $26 \mathrm{~kg} / \mathrm{cm}^{2}$ of control concrete.

A distinctive study was undertaken by Abhishek and Pradeep (2015) to examine the effect of partial replacement of sand with granite quarry dust and cement with marble powder in concrete. The results indicated that the compressive strength increased gradually by adding up to $10 \%$ replacement of cement with marble powder and 20\% replacement of fine aggregate with granite dust. Beyond these proportions of waste addition, the compressive strength of the concrete mix decreased. This was referred to the lack of combination between the $\mathrm{CSH}$ gel and the granite marble wastes during the hydration process leading to a weak micro-structure of concrete.

Bakhoum et al. (2017) presented a study on the use of nano-granite waste particles as a partial replacement of cement and fine aggregate in mortar production. The research concluded that replacing 5\% cement and 10\% sand with nano-granite waste in the mortar mix increased the compressive strength of the green mortar by $41 \%$ compared to that of the control mix (CM). SEM images reinforced this result as the green mortar mix showed maximum density and minimum micro-cracks and a number of pores. The research was extended to study the social, environmental, and economic effects of using granite waste as a partial replacement for both cement and sand simultaneously. Savings in energy consumption and $\mathrm{CO}_{2}$ emissions reached $5 \%$.
This research aims to evaluate the effect of the chemical constituents of both marble and granite wastes as partial replacement to cement and sand on the cement aggregate matrix compression strength.

\section{Materials and methods}

\section{Raw materials}

The materials used in this study were obtained from the local Egyptian market. Normal Portland cement used was CEM I $42.5 \mathrm{~N}$, confirming the Egyptian standards ES 47561. The specific gravity of cement used in this study was $3.15 \mathrm{gm} / \mathrm{cm}^{3}$, and the percentage of fine particles passing from sieve 170 was $9 \%$ which presents the fineness of cement used. The initial and final setting times were $2 \mathrm{~h}$ and $3.2 \mathrm{~h}$, respectively.

Natural sand composed of siliceous materials was used as fine aggregate in this study. The nominal maximum size of the sand was $4.75 \mathrm{~mm}$. The marble and granite waste powder were obtained from Shaqu-Elteban area, Egypt. This fine powder was used to substitute conventional cement and fine aggregates in the green mortar mixes produced. The fine waste material is obtained in the form of slurry material containing various percentage of water. In order to ensure a constant $\mathrm{W} / \mathrm{C}$ ratio for mortar mixes, the natural waste material was dried up using an oven at a temperature of $200^{\circ} \mathrm{C}$ for $6 \mathrm{~h}$. The waste material powder was weighed before and after the drying process, and the difference of weight proved to be less than $10 \%$ to ensure proper drying state of this waste material. The water was clean tap water with a temperature ranging $20-30^{\circ} \mathrm{C}$.

The waste materials were then sieved and the fine particles passing through sieve $300 \mu \mathrm{m}$ were used as a partial replacement of cement. This waste was dissolved in water resulting in a consistent solution which in turn was added to the other mix components to produce the resulting green mortar mixes.

\section{Materials characterization Chemical analysis (XRF)}

$\mathrm{X}$-ray fluorescence spectrometry (XRFS) is a method of elemental analysis that assesses the presence and concentration of various elements by measurement of secondary X-radiation from the sample that has been excited by an X-ray source.

Classically, elements from the heaviest down to atomic number 9 (F) can be determined at levels of a few milligram/kilogram (ppm). Newer developments with wavelength dispersive spectrometers (WDXRF) allow the determination of some of the ultralow atomic number elements including $(\mathrm{O})$.

The instrument XRF analysis is run on an AXIOS, PANalytical 2005, wavelength dispersive sequential 
Table 1 Mix components with marble waste replacement

\begin{tabular}{|c|c|c|c|c|c|c|c|}
\hline \multicolumn{3}{|c|}{ Design mix } & \multicolumn{4}{|c|}{ Components quantity (gm) } & \multirow{2}{*}{$\begin{array}{l}\text { W/C } \\
\text { ratic }\end{array}$} \\
\hline No & Name & Description & Cement & Fine agg. & Marble waste & Water & \\
\hline 1 & CM & Control mix & 277 & 870 & 0.0 & 139 & 0.5 \\
\hline 2 & NC5 & Nano marble waste $5 \%$ cement replacement & 263 & 870 & 14 & 139 & 0.5 \\
\hline 3 & NF10 & Nano marble waste $10 \%$ sand replacement & 277 & 783 & 87 & 139 & 0.5 \\
\hline 4 & $N C 5+N F 10$ & Nano marble waste $5 \%$ Cement $+10 \%$ sand replacement & 263 & 783 & 101 & 139 & 0 \\
\hline
\end{tabular}

spectrometer (WD-XRF), which is installed at the National Research Centre (NRC).

Sample preparation The samples of marble and granite wastes were crushed and then ground in a Herzog type mill to reach fine powder. The ground powder should pass through a $0.063-\mathrm{mm}$ sieve.

\section{Compression test of green mortar}

Specimens The specimens used were cast in cube molds in $50 \times 50 \times 50 \mathrm{~mm}$ and kept for $24 \mathrm{~h}$ and then were cured in curing basins for 28 days. An average of 3 specimens was cast for each mix design.

Design mixes The design mixes used in this study to produce green mortar were prepared by partially replacing cement, sand, and both of them with different percentages by weight of waste material. It should be stated that the $\mathrm{W} / \mathrm{C}$ ratio was 0.5 for all mixes produced.

Table $\mathbf{2}$ Chemical analysis of raw materials

\begin{tabular}{|c|c|c|c|}
\hline Main constituents (wt.\%) & Marble waste & Granite waste & OPC \\
\hline$\overline{\mathrm{SiO}_{2}}$ & 2.32 & 67.85 & 20.55 \\
\hline $\mathrm{TiO}_{2}$ & 0.03 & 0.44 & - \\
\hline $\mathrm{Al}_{2} \mathrm{O}_{3}$ & 0.44 & 15.68 & 4.01 \\
\hline $\mathrm{Fe}_{2} \mathrm{O}_{3}^{\text {tot. }}$ & 0.20 & 3.13 & 3.27 \\
\hline $\mathrm{MnO}$ & - & 0.07 & - \\
\hline $\mathrm{MgO}$ & 0.48 & 0.63 & 1.75 \\
\hline $\mathrm{CaO}$ & 53.75 & 1.43 & 62.67 \\
\hline $\mathrm{Na}_{2} \mathrm{O}$ & 0.09 & 4.51 & 0.44 \\
\hline $\mathrm{K}_{2} \mathrm{O}$ & 0.03 & 4.82 & 0.24 \\
\hline $\mathrm{P}_{2} \mathrm{O}_{5}$ & 0.09 & 0.11 & - \\
\hline $\mathrm{SO}_{3}$ & 0.26 & 0.09 & 3.15 \\
\hline $\mathrm{Cl}$ & 0.04 & 0.05 & 0.02 \\
\hline $\mathrm{BaO}$ & - & 0.171 & - \\
\hline $\mathrm{ZrO}_{2}$ & - & 0.149 & - \\
\hline Minor other oxides & 0.053 & 0.14 & - \\
\hline L.O.I & 42.21 & 0.73 & 3.84 \\
\hline Total & 99.993 & 100 & 99.94 \\
\hline
\end{tabular}

The first mortar mix prepared (CM) was a control mix with a $0 \%$ replacement ratio of waste. The first mortar green mix (NC5) was containing 5\% of marble waste as a partial replacement of cement, while (NF10) was a green mortar containing $10 \%$ of marble waste as a partial replacement of sand. The last green mix (NC5 + NF10) was prepared using 5\% cement replacement and $10 \%$ sand replacement together. Table 1 presents the mixes components produced for this study.

It should be noted that the mix proportions used in this study were selected similar to those done on granite waste powder in Bakhoum et al. (2017) in order to conclude a complete understanding of the behavior of the chemical constituents of marble and granite in mortar mixes.

Compression tests A compressive strength test was carried out for mortar mixes after curing for 28 days. The Shumadsu $1000 \mathrm{KN}$ universal compression machine was used in testing the mortar samples. The machine is equipped with a data analyzing output for data recording.

\section{Results}

Raw material characterization

Chemical analysis (XRF)

Table 2 shows the chemical analyses of the raw materials as obtained from XRF analyses, whereas Table 3 presents the percent of free silica and organic matter of the two wastes. The loss on ignition obtained is significantly higher in case of marble waste than that of granite waste. This is mainly due to the loss of carbon dioxide from the decomposition of marble waste (consisting mainly of calcium carbonate), in addition to the organic matter content as revealed in Tables 2 and 3.

Table 3 Percent of organic matter and free silica of the two wastes

\begin{tabular}{lll}
\hline Raw material & $\begin{array}{l}\text { Marble } \\
\text { waste }\end{array}$ & $\begin{array}{l}\text { Granite } \\
\text { waste }\end{array}$ \\
\hline Organic matter, \% & 7.10 & 3.33 \\
Free silica, \% & 0.85 & 26.33 \\
\hline
\end{tabular}


Table 4 Compressive strength of green mortar with marble waste

\begin{tabular}{lllll}
\hline Mix & CM & NC5 & NF10 & NC5 + NF10 \\
\hline Compressive strength $\left(\mathrm{kg} / \mathrm{cm}^{2}\right)$ & 251 & 216 & 263 & 255 \\
\hline
\end{tabular}

Compression test results The compression tests were carried out to investigate the mechanical behavior of green mortar mixes prepared using marble waste powder. Table 4 presents the compression test results for mortar mixes at a curing time of 28 days.

\section{Discussion}

Test results show that for the control mix $(\mathrm{CM})$, the compression strength was $251 \mathrm{~kg} / \mathrm{cm}^{2}$. By replacing $5 \%$ of cement with marble powder in NC5, the compressive strength value dropped by $14 \%$. For sand replacement, and by replacing $10 \%$ of sand with marble powder in (NF10), the compressive strength value rises up to 5\% above the control CM. Replacing 5\% of cement and 10\% of sand with marble waste powder in NC5 + NF10 mix gives almost the same compressive strength value obtained from CM.

Comparing these results of marble replacement to those of granite with the same mixing proportions cited in Bakhoum et al. (2017), the results of green mortar using granite waste powder in Table 5 showed an increase in the compressive strength for all mixes NC5, NF10, and NC5 + NF10, of $33 \%, 39 \%$, and $41 \%$, respectively.

The probable reason for that behavior is the presence of a relatively large amount of fine free silica particles in granite as evidenced from Table 3 . The table shows that granite waste contains more than $26 \%$ fine free silica particles. These particles will undergo pozzolanic reaction with calcium hydroxide present in mortar pores producing $\mathrm{CSH}$ crystals which result in high strength to the cement mortar. On the other hand, marble waste is largely composed of limestone (Table 2 ) which possesses no pozzolanic properties.

This result concedes with those presented by Manpreet et al. (2017a, 2017b), which revealed that the increase in compressive strength is observed only due to micro-filler effect of marble powder whereas a decrease in strength begins to appear at $10 \%$ substitution as the amount of C3A and $\mathrm{C} 2 \mathrm{~S}$ required for hydration process reduces.

Table 5 Compressive strength of green mortar with granite waste cited in Bakhoum et al. (2017)

\begin{tabular}{lllll}
\hline Mix & CM & NC5 & NF10 & NC5 + NF10 \\
\hline Compressive strength $\left(\mathrm{kg} / \mathrm{cm}^{2}\right)$ & 263 & 349 & 365 & 372 \\
\hline
\end{tabular}

\section{Conclusion and recommendations}

Marble waste has a high percentage of fines but does not have a considerable amount of silica and alumina. Calcite and dolomite are the main constituents present in the marble slurry. Replacing cement and sand by marble waste did not result in a significant increase in the cement mortar compressive strength when compared to the control mix.

Granite waste contains more than 26\% fine free silica particles which undergo pozzolanic reaction with calcium hydroxide present in mortar pores. This pozzolanic reaction produces $\mathrm{CSH}$ crystals which increase the strength of the cement mortar.

This result is corroborating with the chemical composition analysis conducted by Bruna et al. (2018), which revealed that the main components of the granite waste were silica (42.80\%), calcium oxide (19.00\%), and aluminum trioxide $(8.07 \%)$ together with small amounts of other oxides.

Although the waste particles worked as filler, it was observed that its presence in the mixture improved the particle packing and increased the cohesion of the composites.

For future work, it is highly recommended to study the effect of using both marble and granite wastes together as a partial replacement to cement and sand on the cement aggregate matrix with different mixing proportions to reach the optimum green mortar compression strength results.

\section{Acknowledgements}

Authors would like to acknowledge the technicians who worked for this research from the Civil Engineering Department at NRC.

\section{Authors' contributions}

SA performed the chemical laboratory analysis tests for raw materials, and $\mathrm{SA}, \mathrm{HE}$, and MA performed the compression mechanical test. MA, SA, and GG analyzed and interpreted the results of chemical analysis and compression test values obtained, and all authors read and approved the final manuscript.

\section{Funding}

This work was supported by the National Research Centre, Egypt, as a part of the Internal Projects program 2017-2019.

\section{Availability of data and materials}

The datasets used and/or analyzed during the current study are available from the corresponding author on reasonable request.

Ethics approval and consent to participate

Not applicable

Consent for publication

Not applicable

\section{Competing interests}

The authors declare that they have no competing interests.

\section{Author details}

${ }^{1}$ Chemical Engineering and Pilot Plant Department, Engineering Research Division, National Research Centre, Dokki, Egypt. ${ }^{2}$ Civil Engineering 
Department, Engineering Research Division, National Research Centre, Dokki, Egypt.

Received: 10 January 2019 Accepted: 20 January 2020

Published online: 04 February 2020

\section{References}

Abhishek M, Pradeep KG (2015) Effect on strength and durability properties of concrete incorporating granite and marble residues as fillers. Int I Civil Eng Technol (IJCIET) 6(11):173-183

Bacarji E, Filho RDT, Koenders EAB, Figueiredo EP, Lopes JLMP (2013)

Sustainability perspective of marble and granite residues as concrete fillers. Constr Build Mater 45:1-10

Bahar D (2010) The effect of the using waste marble dust as fine sand on the mechanical properties of the concrete. Int J Phys Sci 5(9):1372-1380

Bakhoum E, Garas GL, Allam ME, Ezz H (2017) The role of nano-technology in sustainable construction: a case study of using nano granite waste particles in cement mortar. Eng J 21(4):217-227

Bruna SA, Fernanda GP, Luciane SCM, White JS, Maria TPA (2018) Study of Portland cement composites replacing cement for waste from the cutting and polishing of ornamental rocks. Int J Sci Eng Invest 7(76):120-124

Hamza R, El-Haggar S, Khedr S (2011) Utilization of marble and granite waste in concrete bricks. Int Conf Env Biosci IPCBEE 21

Manpreet S, Anshuman S, Dipendu B (2017b) An investigation on effect of partial replacement of cement by waste marble slurry. Cons Building Mat 134:471-488

Manpreet S, Pankaj L, Anshuman S, Dipendu B (2017a) Long term effect of partially replacing cement by waste marble slurry in concrete. Cong Tech Adv. https://doi.org/10.1061/9780784481035.007

Ramos T, Matos AM, Schmidt B, Rio J, Sousa-Coutinho J (2013) Granitic quarry sludge waste in mortar: effect on strength and durability. Constr Build Mater 47:1001-1009

Sarbjeet S, Anshuman T, Ravindra N (2015) Comparative assessment of effects of sand \& cement replacement in concrete by marble dust \& in turn deriving an optimum design mix for concrete paver blocks. Conference Paper: Global Stone Technology Forum (GSTF)

Shehdeh G (2016) Comparison between concrete with granite powder and concrete with iron powder. Int J Appl Eng Res 11(21):10501-10515

\section{Publisher's Note}

Springer Nature remains neutral with regard to jurisdictional claims in published maps and institutional affiliations.

\section{Submit your manuscript to a SpringerOpen ${ }^{\circ}$ journal and benefit from:}

- Convenient online submission

- Rigorous peer review

- Open access: articles freely available online

- High visibility within the field

- Retaining the copyright to your article

Submit your next manuscript at $\boldsymbol{\nabla}$ springeropen.com 